\title{
Erratum to: Design of Family and Child Welfare Policy in Indonesia
}

\author{
hammad Adnan*1 \\ ${ }^{1}$ Government Studies, Universitas Diponegoro, Indonesia
}

Original article: E3S Web of Conferences 73, 09006 (2018), https://doi.org/10.1051/e3sconf/20187309006

The Author of the article should be replaced by the following text:

Muhammad Adnan*1

${ }^{1}$ Government Studies, Universitas Diponegoro, Indonesia 